\title{
DIVISION IX / COMMISSION 30 / WORKING GROUP STELLAR RADIAL VELOCITY BIBLIOGRAPHY
}

CHAIR
VICE-CHAIR

\author{
Hugo Levato \\ Stella M. Malaroda
}

TRIENNIAL REPORT 2006 - 2009

\section{Introduction}

The Working Group Stellar Radial Velocity Bibliography is a very small one that was created with the purpose of continuing the cataloging of bibliography of radial velocity of stars made by Mme Barbier in successive catalogues until her retirement in 1990.

We have started the new compilation late in 1990. The first version of the catalogue after the retirement of Mme Barbier was published for the triennium 1991-1994 at <www.casleo.gov.ar/catalogo/>. The catalogue is updated at this page each six months.

\section{Developments within the triennium}

During the triennium 2006 - 2009, the WG searched for the papers with measurements of radial velocities of stars among 33 journals. By December 2007 we had cataloged 113658 entries. We expect to finish 2008 with around 150000 . It is worth to mention that at the end of 1996 we had recorded 23358 entries, so in 10 years the number of entries in the catalogue multiplied by five.

During the triennium we have improved the search engine to search by different parameters. In the main body of the catalogue we have included information about the technical characteristics of the instrumentation used for radial velocity measurements and comments about the nature of the objects.

\section{Closing remarks and future}

The future is becoming very attractive. New tools permit to increase the efficiency of the search. During the last year search engines like SCOPUS from Elsevier Publishers was under test. 